\title{
A study of aqueous humour proteins in patients of primary open angle glaucoma
}

\author{
Meena Zaidi $^{{ }^{*}}$, Azra Jilani ${ }^{1}$, Padmawati Bhattacharya ${ }^{1}$, Najmul Islam ${ }^{2}$, Shahid Alam ${ }^{1}$ \\ ${ }^{1}$ Institute of Ophthalmology, JawaharLal Nehru Medical College, Aligarh Muslim University, Aligarh, India; \\ ${ }^{2}$ Department of Biochemistry, JawaharLal Nehru Medical College, Aligarh Muslim University, Aligarh, India. \\ Email: meenazaidi@rediffmail.com
}

Received 15 March 2010; revised 7 April 2010; accepted 9 April 2010.

\begin{abstract}
Aims: To investigate the changes in the protein composition of aqueous humour in primary open angle glaucoma patients and non-glaucomatous subjects. Patients and Methods: Case control study was conducted at a university hospital to compare the protein profile of aqueous humour obtained from patients of primary open angle glaucoma with those of nonglaucomatous subjects. Protein concentration of the aqueous humour samples collected from both glaucomatous and non-glaucomatous patients at the time of surgery was estimated by the Bradford protein assay method. Sodium dodecylsulfate polyacrylamide gel electrophoresis of the samples was also performed. Results: Geometric mean of protein concentration of the samples was $55.73 \mathrm{mg} / \mathrm{dl}$ (range: 31-72) in the test group and $46.46 \mathrm{mg} / \mathrm{dl}$ (range: $27-65$ ) in the control group and a statistically significant $(p \leq=0.001)$ difference in protein concentration of aqueous humour between the two groups was observed. Electrophoretic study revealed differences in the aqueous protein composition of the two groups. The glaucomatous group exhibited protein bands of $10 \mathrm{kDa}, 20 \mathrm{kDa}$, $30 \mathrm{kDa}, 50 \mathrm{kDa}, 60 \mathrm{kDa}, 70 \mathrm{kDa}$, and $90 \mathrm{kDa}$ while the control subjects demonstrated bands of $6 \mathrm{kDa}, 10$ kDa, 30 kDa, 70 kDa, 90 kDa. Interestingly, almost all the proteins detected in this study corresponded to the molecular weights of heat shock proteins. Conclusions: Primary open angle glaucoma patients differed in protein compositions and had higher concentration of aqueous humour proteins than nonglaucomatous patients.
\end{abstract}

Keywords: Aqueous Humour; Open Angle Glaucoma; Proteins

\section{INTRODUCTION}

Adult-onset primary open-angle glaucoma (POAG) is the most common form of glaucoma, usually manifest- ing itself after the age of 40 years. The prevalence of POAG is about $1-2 \%$ over age 40 years in white populations and 3-4 times greater in black populations of the same age [1]. Recent projections estimate that worldwide, 60.5 million people will suffer from some form of glaucoma by 2010 , with primary open angle glaucoma (POAG) accounting for about $74 \%$ of cases [2].

Unfortunately, despite the magnitude of the problem, the accurate etiopathogenesis of this silent stealer of sight still remains a mystery. Compared to other forms of glaucoma, the optic neuropathy of POAG is multifactorial, with IOP, being the most important risk factor [3]. It is also the only risk factor that is therapeutically modifiable.

It is generally believed that like all other forms of glaucoma, it is ultimately a mechanical blockade of aqueous outflow that increase IOP of POAG. But the exact cause or site of this blockade is yet to be definitely determined. However, a change in the composition of aqueous humor prevents its smooth outflow. Normally, aqueous humour has $0.02 \%$ protein $(20 \mathrm{mg} / \mathrm{dl})$ as compared with $7 \%$ reported in plasma. In a study, the total protein concentration in primary open-angle glaucoma aqueous humour was approximately two times higher than that in non-glaucomatous subjects [4]. The most abundant protein identified in aqueous humour is albu$\min (50 \%$ of all the protein content) and transferrin, when analysed by high performance gel filtration chromatography (HPGFC) [5] or by crossed immuneelectrophoresis [6] or SDS-PAGE [7]. However, biochemical investigation of the aqueous, considering such aspect in the various forms of open angle glaucoma, has so far received relatively little attention. Due to lack of sufficient information on the role of proteins involved in the pathogenesis of open angle glaucoma (especially POAG), the present study was undertaken to assess the changes in the protein composition of aqueous humour of primary open angle glaucoma and to compare it with those of non-glaucomatous patients. A better understanding of the mechanism of POAG is likely to lead to more effective treatment of this disease. 


\section{PATIENTS AND METHODS}

This was a case-control study conducted at a university hospital of Aligarh Muslim University, India, between November 2007 to September 2008. An informed written consent was obtained from all the chosen patients following the guidelines of Helsinki Declaration. The patients were divided into two groups - (Group I) TEST group included patients above 50 years old with established cases of primary open angle glaucoma undergoing trabeculectomy due to uncontrolled intraocular pressure with optimal medical therapy. The diagnostic criteria for primary open-angle glaucoma were: 1) presence of glaucomatous optic disc damage 2) corresponding glaucomatous changes in the visual field 3) open angle of anterior chamber 4) absence of alternative causes of optic neuropathy (e.g., infection, inflammation, meningeal disease, ischemic disease, and compressive lesions) and 5) no features of secondary glaucomas. Group II (Control group) included, age matched patients of senile cataract, without any evidence of glaucoma, undergoing cataract surgery. The following criteria were used for exclusion for both groups: 1) evidence of ocular surgery including laser within 6 months 2) evidence of intraocular inflamemation 3) complicated cataract 4) history of uveitis 5) history of ocular trauma and 6) diabetic retinopathy.

\subsection{Sample Collection}

Aqueous humour samples were collected at the beginning of the surgery, before entering the anterior chamber. A $0.1 \mathrm{ml}$ aqueous humour fluid was removed from the anterior chamber under sterile conditions using a tuberculin syringe and stored in microtubes at $-20^{\circ} \mathrm{C}$ until analysis. All surgical procedures were performed by experienced ophthalmic surgeons. The protein contents in the aqueous humor were estimated following the method of Bradford [8]. The molecular weight of proteins in aqueous humour of the test and control samples were analyzed by sodium dodecylsulfate polyacrylamide gel electrophoresis (SDS-PAGE).

\section{RESULTS}

The geometric mean of total protein concentration of the aqueous humor samples was $55.73 \mathrm{mg} / \mathrm{dl}$ (ranging from 31 to $72 \mathrm{mg} / \mathrm{dl}$ ) in the POAG group and $46.46 \mathrm{mg} / \mathrm{dl}$ (ranging from 27 to $65 \mathrm{mg} / \mathrm{dl}$ ) in the control group. The difference in the protein contents of the two groups was statistically significant $(\mathrm{p} \leq 0.001)$. Furthermore, a remarkable difference in the electrophoretic patterns of the protein in aqueous humour of the two groups was observed when analysed by sodium dodecyl sulfate polyacrylamide gel electrophoresis (SDS-PAGE). Seven well defined protein bands of molecular weight $10 \mathrm{kDa}, 20$ $\mathrm{kDa}, 30 \mathrm{kDa}, 50 \mathrm{kDa}, 60 \mathrm{kDa}, 70 \mathrm{kDa}, 90 \mathrm{kDa}$ were detected in the POAG group (Figure 1). In contrast, the control group exhibited fewer protein bands whose molecular weights were $10 \mathrm{kDa}, 30 \mathrm{kDa}, 70 \mathrm{kDa}, 90 \mathrm{kDa}$. Thus, in this study, the $20 \mathrm{kDa}, 50 \mathrm{kDa}$ and $60 \mathrm{kDa}$ proteins were detected only in the samples collected from the patients suffering from POAG. The $70 \mathrm{kDa}$ protein
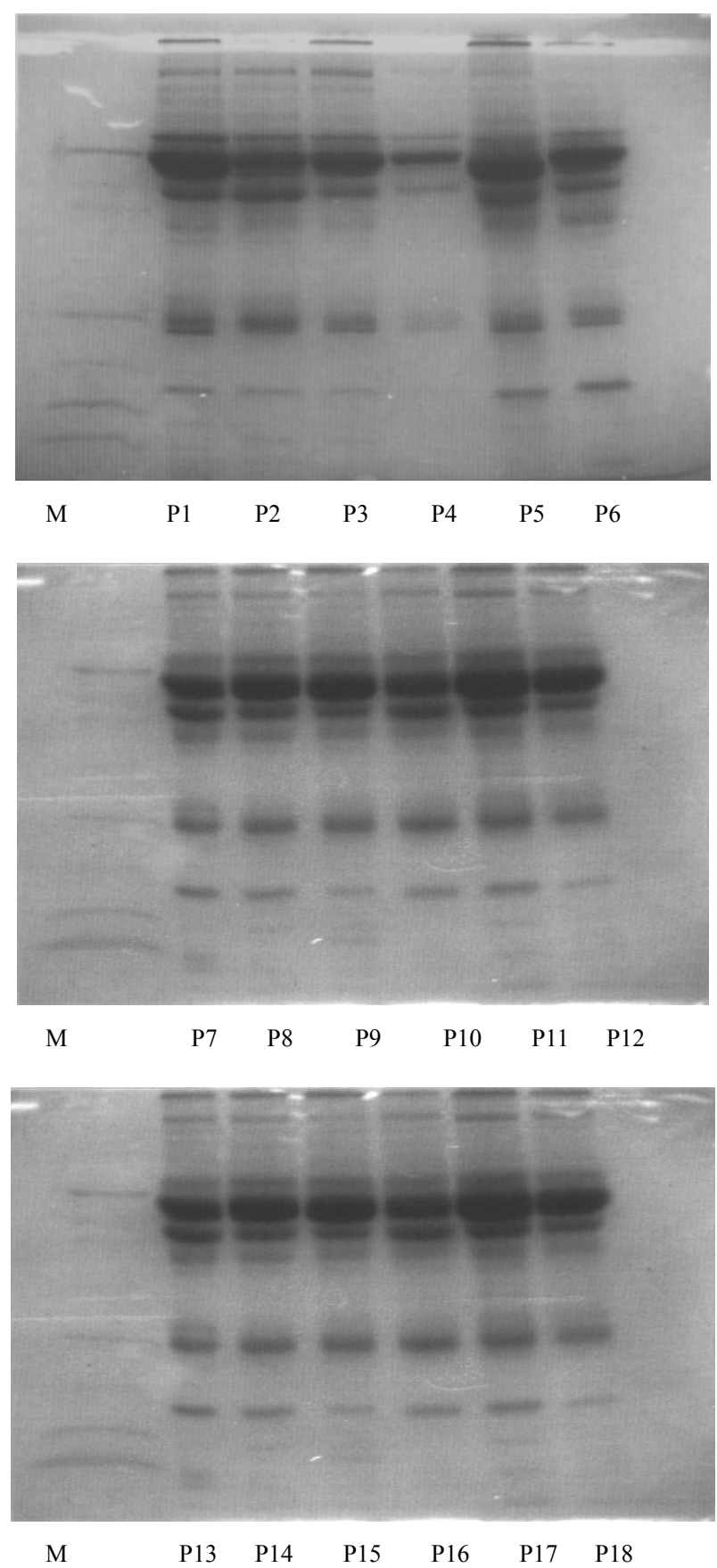

Figure 1. SDS-PAGE of protein lysates in aqueous humour of POAG group. Lanes P1 to P18 represents patient samples while lane $\mathrm{M}$ represents standard molecular weight marker. 
though detected in both the groups, it exhibited a suppressed expression on gel in the controls relative to the POAG group. Among the POAG group samples, 24 had a higher magnitude expression while two showed only appreciable magnitude expression. On the contrary, proteins of varying molecular weight between 71-90 kDa were over expressed and densely stained in controls and, hence, finer resolution into separate molecular weights was not possible.

Another interesting observation of this study was the expression of a $60 \mathrm{kDa}$ protein in aqueous humour samples of POAG patients which was not detected in control samples. However, except for two cases, $92.3 \%$ of the total POAG group samples demonstrated a low magnitude expression of $60 \mathrm{kDa}$ protein. Of the $26 \mathrm{POAG}$ group samples, $84.6 \%$ (22 samples) showed low magnitude expression of $50 \mathrm{kDa}$ proteins whereas aqueous humour of controls showed no such protein bands during SDS-PAGE analysis. Generally, the $30 \mathrm{kDa}$ protein, like the $70 \mathrm{kDa}$ protein, was detected in all samples of both the POAG and control samples. Of the total 26 POAG samples, $80.76 \%$ (21 samples) displayed low magnitude expression of $20 \mathrm{kDa}$ protein, but none of the control samples showed the protein of such molecular weight. Though, the $10 \mathrm{kDa}$ protein was expressed in the samples of each group, $60 \mathrm{kDa}$ protein was recorded only in one control sample.

\section{DISCUSSION}

Outflow facility is reported to be significantly reduced in patients with uveitis who have high aquous humour protein level. Such elevated aqueous humour protein level in turn, leads to the development of glaucoma by decreasing aqueous humour outflow facility [9]. Therefore, we analyzed and compared the concentration of total proteins in both glaucomatous and non-glaucomatous patients. In our SDS-PAGE analysis of the test sample, we found that not only the total aqueous protein concentration increased in POAG, but also the aqueous protein composition differs from non-POAG eyes. The differences in protein concentrations in POAG patients cannot be attributed to the drug because increase in protein concentration in aquous humor is reported only in topical application of timilol and is not reported by other topical anti-glaucoma drugs. Further, the increase in protein concentration is not due to increase in protein production but is due to reduced concentration of aquous humor. So, this is not likely to alter the chemical composition of protein in aquous humor $[10,11]$. Furthermore, increase in the total concentration of proteins in aqueous humor after oral administration of $500 \mathrm{mg}$ of acetazolamide has also been reported [12]. The effect of this drug on the protein concentrations of the POAG patients, who were using it, can be ruled out because two dosage of acetazolamide is routinely administered as pre-operative medication before cataract surgery at our centre.

In other study, the PG analogues though induced MMPs but the molecular weight of protein observed in our study was smaller than those reported for PG induced proteins in the ciliary body [13]. However, unlike the findings of Herschler et al. [14] or Lee et al. [15] we did not record any high molecular proteins in the aqueous humor obtained from patients of primary open angle glaucoma. Interestingly, almost all the proteins detected in this study had molecular weights corresponding to the heat shock proteins (Hsp). Synthesis of such heat shock proteins has been found in vivo and in organ cultures of several mammalian tissues which were subjected to heat shock or other forms of stress $[16,17]$. Heat shock proteins act as protective proteins and aid in maintaining cellular homeostasis under environmental stress [18-20]. Some of the common stressors include heat shock, ischemia, oxidative stress, $\mathrm{pH}$ extremes, nutrient limitation, osmotic variation, hypoxia etc. Of the various heat shock proteins, Hsp 70 is normally produced by the epithelial cells of the natural lens and retinal ganglion cells even in unstressed conditions. However, heat shock proteins can be expressed constitutively or be induced but its production is reported to be increased by cellular stress [21]. This may be the reason a $70 \mathrm{kDa}$ protein was though observed in both POAG and control groups, but it was over expressed in the POAG group only. The 60 $\mathrm{kDa}$ protein noticed in $92.3 \%$ of the POAG samples was not found in any of the samples collected from controls subjects. In similar studies, Tripathi [22] reported a 60 $\mathrm{kDa}$ protein in aqueous humor of cataract cases while serum auto antibodies to Hsp 60 in various open angle glaucomas, including POAG is also reported [23]. Increased expression of Hsp 60 has been observed in retina and optic nerve head in human donor eyes with glaucoma [24].

The $\mathrm{kDa} 50$ fraction was the only protein expressed in the study samples whose molecular weight does not correspond to a heat shock protein. Plasminogen activator inhibitor1(PAI-1), an approximately $50 \mathrm{kDa}$, inducible protein has been reported to be increased in aqueous humor of open angle glaucoma patients by Dan et al. [25]. The tPA and uPA, the target enzymes for PAI-1, were previously detected in the human aqueous humour [26,27]. Previously it was roughly estimated that most of the tPA was complexed with PAI-1, with only a small free fraction available for proteolysis [27]. Thus, the equilibrium may normally be shifted, perhaps delicately, toward fibrinolysis and proteolysis, which could be involved in the maintenance of aqueous outflow. Our results suggest that this situation may be reversed in patients with glaucoma owing to the increase in PAI-1 level in the aqueous humor. However, our study did not specifically identify this $50 \mathrm{kDa}$ fraction. Moreover, none of the controls exhibited this fraction, a finding which is at 
variance with other studies.

Small heat shock proteins (sHsps) are a large family of proteins with monomeric molecular weight of 12-43 $\mathrm{kDa}$. Unlike the high molecular weight Hsps, which are involved in protein folding in vivo, under normal conditions, sHsps play an important role in protecting organism from stress. Such small heat shock proteins are reported to share an evolutionarily conserved sequence of 80-100 amino acids, located in the C-terminal region, called the alpha-crystallin [28]. Tamm et al. [20] have demonstrated that both monkey and human TM cell cultures stressed by heat shock, exhibited a significant increase in alpha B-crystallin mRNA. In this context, it must be emphasised that the cellular consequences of heat and ischemia are similar. Albumin, the major aqueous humor protein, acts as a escort through the trabecular meshwork in mammalian eyes, and interacts with alpha-crystallin up to the critical micelle concentration for alpha-crystallin $(3.5-5 \mathrm{mg} / \mathrm{ml}$ or $0.18-0.25 \mathrm{mM})$ as reported by Doss et al. [29]. There is little in- teraction at or above this concentration. This binding could serve the necessary function of preventing interactions between alpha-crystallin monomers or small aggregates and hydrophobic surfaces within the trabecular meshwork. However, since the interaction between the two proteins is not very strong, the accumulation of unbound monomers/dimers of alpha-crystallin could contribute to the development of primary open angle glaucoma.

Assuming that the $20 \mathrm{kDa}$ protein detected in POAG cases in our study is Hsp 20, we would like to take this hypothesis forward. What we propose is that glaucoma causes conditions of stress, which results in over expression of alpha-crystallin by the trabecular meshwork. This increased production of alpha-crystallin, overwhelms the capacity of albumin to escort it through the trabecular meshwork. This results in excess being secreted into the aqueous humor, and consequent blockade by alphacrystallin monomers/dimer. This hypothesis is also in agreement with the observations of others [30,31]. After in vitro studies they concluded that the filter blocking process involves two interacting classes of blocking components, which when present simultaneously in aqueous humor, bind hydrophobically to the filtering surface. Based on these observations, it was suggested that one of the members could be albumin, the dominant protein of aqueous humor. Filtration blockage would also require a second component leading to the synthesis of $20 \mathrm{kDa}$ protein as observed in our study.

In conclusion, our study revealed that primary open angle glaucoma patients had higher concentration of aqueous humor proteins than controls and that the protein composition of the aqueous humor samples was different from the normal ones. Furthermore, various protein bands detected by SDS-PAGE needs to be quali- fied and to establish that $20 \mathrm{kDa}$ protein is indeed an alpha-crystallin. Small molecular weight aqueous humor proteins and trabecular meshwork immunohistochemistry needs further investigation to determine the etiopathogenesis of primary open angle glaucoma. Our study provides an early marker in this direction.

\section{REFERENCES}

[1] Sommer, A., Tielsch, J.M., Katz, J., et al. (1991) Relationship between intraocular pressure and primary open angle glaucoma among white and black patients: the Baltimore Eye Survey. Archives of Ophthalmology, 109(8), 1090-1095.

[2] Quigley, H.A. and Broman, A.T. (2006) The number of people with glaucoma worldwide in 2010 and 2020. British Journal of Ophthalmology, 90(3), 262-267.

[3] Quigley, H.A. (1996) Number of people with glaucoma worldwide. British Journal of Ophthalmology, 80(5), 389393.

[4] Prata, T.S., Navajos, E.V., Melo, L.A., Jr., et al. (2007) Aqueous humor protein concentration in patients with primary open angle glaucoma under clinical treatment. Arquivos Brasileiros de Oftalmologia, 70(2), 217.

[5] Saari, K.M., Aine, E. and Parvianen, M. (1983) Determination of protein content in aqueous humour by highperformance gel filtration chromatography. Acta Ophthalmologia (Copenh), 61(4), 611-617.

[6] Inada, K., Muarata, T., Baba, H., et al. (1988) Increase of aqueous humor proteins with aging. Japanese Journal of Ophthalmology, 32(2), 126-131.

[7] Tripathi, R.C., Millard, C.B. and Tripathi, B.J. (1989) Protein composition of human aqueous humor: SDSPAGE analysis of surgical and post-mortem samples. Experimental Eye Research, 48(1), 117-130.

[8] Bradford, M.M. (1976) A rapid and sensitive method for the quantitation of microgram quantitites of protein utilizing the principle of protein-dye binding. Analytical Biochemistry, 72(1-2), 248-254.

[9] Ladas, J.G., Fei, Y., Loo, R., et al. (2001) Relationship between aqueous humour protein level and outflow facility in patients with uveitis. Investigative Ophthalmology and Visual Science, 42(11), 2584-2588.

[10] Stur, M., Grabner, G., Huber-Spitzy, V., Schreiner, J. and Haddad, R. (1986) Effect of timolol on aqueous humor protein concentration in the human eye. Archives of Ophthalmology, 104(6), 899-900.

[11] Beardsley, T.L. and Shields, M.B. (1983) Effect of timolol on aqueous humor protein concentration in humans. American Journal of Ophthalmology, 95(4), 448450.

[12] Oshika, T. and Araie, M. (1990) Time course of changes in aqueous protein concentration and flow rate after oral acetazolamide. Investigative Ophthalmology and Visual Science, 31(3), 527-534.

[13] Shahid, H., Farahdiba, J. and Crosson, C.E. (2005). Acute effects of $\mathrm{PGF}_{2 \alpha}$ on MMP-2 secretion from human ciliary muscle cells: A PKC- and ERK-dependent process. Investigative Ophthalmology and Visual Science, 46(5), 17061713. 
[14] Herschler, J. and Litin, B.S. (1987) Biochemical abnormalities in the aqueous in chronic open angle glaucoma. Ophthalmic Surgery, 18(11), 792-795.

[15] Lee, I.S., Yu, Y.S., Kim, D.M., et al. (1990) Detection of specific proteins in the aqueous humor in primary open angle glaucoma. Korean Journal of Ophthalmology, 4(1), $1-4$.

[16] Bagchi, M., Katar, M. and Maisel, H. (2002) Effect of exogenous stress on the tissue-cultured mouse lens epithelial cells. Journal of Cell Biochemistry, 86(2), 302-306.

[17] Banh, A., Vijayan, M.M. and Sivak, J.G. (2003) Hsp70 in bovine lenses during temperature stress. Molecular Vision, 9, 323-328.

[18] Barbe, M.F., Tytell, M., Gower, D.J. and Welch, W.J. (1988) Hyperthermia protects against light damage in the rat retina. Science, 241(4874), 1817-1820.

[19] Tanaka, Y., Kobayashi, K., Kita, M., et al. (1996) Expression of $47 \mathrm{kDa}$ heat shock protein (Hsp47) during development of mouse cornea. Experimental Eye Research, 63(4), 383-393.

[20] Tamm, E.R., Russell, P., Johnson, D.H. and Piatigorsky, J. (1996) Human and monkey trabecular meshwork accumulate alpha B-crystallin in response to heat shock and oxidative stress. Investigative Ophthalmology and Visual Science, 37(12), 2402-2413.

[21] Yao, K., Rao, H., Wu, R., et al. (2006) Expression of Hsp70 and Hsp27 in lens epithelial cells in contused eye of rat modulated by thermotolerance or quercetin. $\mathrm{Mo}$ lecular Vision, 12, 445-450.

[22] Tripathi, R.C., Borisuth, N.S., Tripathi, B.J., et al. (1992) Quantitative and qualitative analysis of transferrin in aqueous humor from patients with primary and secondary glaucoma. Investigative Ophthalmology and Visual Science, 33(10), 2866-2873.

[23] Wax, M. (2001) Serum autoantibodies to heat shock pro- teins in glaucoma patients from Japan and the United States. Ophthalmology, 108(2), 296-302.

[24] Tezel, G., Hernandez, R. and Wax, M.B. (2000) Immunostaining of heat shock proteins in the retina and optic nerve head of normal and glaucomatous eyes. Archives of Ophthalmology, 118(4), 511-518.

[25] Dan, J., Belyea, D., Gertner, G., et al. (2005) Plasminogen activator inhibitor-1 in the aqueous humor of patients with and without glaucoma. Archives of Ophthalmology, 123(2), 220-224.

[26] Wang, Y., Taylor, D.M., Smalley, D.M., Cone, R.E. and O'Rourke, J. (1994) Increased basal levels of free plasminogen activator found in human aqueous humor. Investigative Ophthalmology and Visual Science, 35(9), 35613566.

[27] Bernatchez, S.F., Tabatabay, C. and Belin, D. (1992) Urokinase-type plasminogen activator in human aqueous humor. Investigative Ophthalmology and Visual Science, 33(9), 2687-2692.

[28] Lee, S., Carson, K., Rice-Ficht, A. and Good, T. (2005) Hsp20, a novel $\alpha$-crystallin, prevents A $\beta$ fibril formation and toxicity. Protein Science, 14(3), 593-601.

[29] Doss, E.W., Ward, K.A. and Koretz, J.F. (1998) Investigation of the "fines" hypothesis of primary open angle glaucoma: The possible role of alpha-crystallin. Ophthalmic Research, 30(3), 142-156.

[30] Ethier, C.R., Kamm, R.D., Johnson, M., et al. (1989) Further studies on the flow of aqueous humor through microporous filters. Investigative Ophthalmology and Visual Science, 30(4), 739-746.

[31] Pavao, A.F., Lee, D.A., Ethier, C.R., et al. (1989) Twodimensional gel electrophoresis of calf aqueous humor, serum, and filter-bound proteins. Investigative Ophthalmology and Visual Science, 30(4), 731-738. 